\title{
Dual Band Square Planar Dipole Antennas with Interdigital Capacitors for Base Stations
}

\author{
Pongsathorn CHOMTONG ${ }^{1}$, Prayoot AKKARAEKTHALIN ${ }^{2}$ \\ ${ }^{1}$ Dept. of Teacher Training in Electrical Engineering, Faculty of Technical Education \\ ${ }^{2}$ Dept. of Electrical and Computer Engineering, Faculty of Engineering \\ King Mongkut's University of Technology North Bangkok, 1518 Pracharat 1 Road, Bangsue, Bangkok, Thailand
}

pongsathornc@kmutnb.ac.th,prayoot@kmutnb.ac.th

Submitted August 3, 2016 / Accepted April 7, 2017

\begin{abstract}
A dual band antenna based on the square planar dipole structure with interdigital capacitors is proposed. With this technique, the harmonic frequency band can be controlled as desired. The dipole element consists of two square copper plates with overall size of $21.6 \times 13.8 \mathrm{~cm}^{2}$. The bandwidths of the proposed antenna are $170 \mathrm{MHz}$ (1.71-1.88 GHz) and $200 \mathrm{MHz}(5.15-5.35 \mathrm{GHz})$. The antenna gain of each band is obtained to be $10 \mathrm{~dB}$ and $8 \mathrm{~dB}$, respectively. To increase the antenna gain, the array antenna composing of the two designed dipoles is studied. The size of array antenna is $21.6 \mathrm{~cm} \times 24.4 \mathrm{~cm}$. The improved gains of $13.1 \mathrm{~dB}$ for the first band and $10.1 \mathrm{~dB}$ for the second band are obtained. The array antenna with four dipoles is also investigated. The high gains of $16.8 \mathrm{~dB}$ for the first band and $12.6 \mathrm{~dB}$ for the second band are obtained. The proposed array antennas have higher gains compared with the conventional array antennas with the same element numbers. Therefore, the proposed antennas can be suitably used for LTE and WLAN base stations.
\end{abstract}

\section{Keywords}

Square dipole antenna, array antenna, interdigital technique

\section{Introduction}

Development of wireless communication systems has been continuously increased to support user demands in daily life. Antenna is an important part of any wireless system used for receiving and sending information. Improvement of antenna characteristics including return loss and gain is needed to serve long distance communications. Also, nowadays some modern antennas with multiband operation are required. However, to design antennas, appropriate size, ease of design, and affordable cost must be carefully considered. Also, higher power handling capacity is necessarily required for base station antenna design. Currently, the base station antennas with multiband operation have been developed continuously for both indoor and outdoor applications. There are different types of base station antennas, especially, using microstrip and metal plate structures. Many of them are designed based on the dipole and monopole antenna structures, whose radiation patterns are commonly omnidirectional. The advantage is that the signals can be received or transmitted around the antenna, but there are low gains. For multiband antenna design, various techniques were proposed such as fractal antennas [1-3]. However, the antenna sizes were large about half wavelength and antenna gains were still low. Also, the fractal antenna radiation patterns are very difficult to be controlled. Another technique is to design the wideband antennas with built-in notches creating multiband responses [4-6]. Nevertheless, it is still difficult to design antennas with higher gain. To improve antenna gains, some reflectors were applied [7-9]. Using the reflectors, interferences between back lobes and side lobes are significantly reduced. Another technique to increase antenna gain was to use genetic algorithm optimization for suitable array antenna geometry and feed position, but complicated computation was required [10]. Also, antenna array could be applied for higher gain, but large number of antenna elements may be required, resulting in large size.

For base station antenna design, high power handling capacity is a main concern. Therefore, dielectric loss or breakdown of material used to build up the base station antenna must be carefully determined. The indoor base station antennas with low power handling capacity were designed to spread omnidirectional or directional patterns but the antenna gains were low [11], [12]. Some outdoor base station antennas in [13-15] were developed by using metal materials for high power handling, resulting in high gain as $17 \mathrm{~dB}$. These antenna structures are very complicated to design and their sizes are also too large. However, these proposed base stations could not support multiband operation. Up to now, several multiband base station antennas were proposed. A dual band base station antenna using U-shaped planar slots was proposed for WLAN and WiMAX applications. However, implementation of both radiation elements and the feed network of this antenna was somehow difficult [16]. Also, the antenna gain and power handling capacity are obviously low. The dual-band base-station antenna whose high-frequency elements are embedded in low frequency elements to reduce volume was 
also proposed in [17]. This antenna has a low profile but there is a limitation in impedance matching for both bands. It is found that not only its structure is very complicated but also the gain and power handling capacity are low.

This paper presents dual band antennas to be used as indoor and outdoor base station antennas. The proposed antennas will be designed using a simple structure on copper plates for improved characteristics and power handling capacity. The antenna structure is based on the dipole with built-in interdigital capacitors and a reflector. The advantage of the proposed antennas is that the second harmonic frequency band can be freely tuned as desired. This paper is divided into two main parts; the single dipole element with interdigital capacitors and the array antenna design for increasing gain. The details of antenna design will be given in Sec. 2. In Sec. 3, the antenna implementation and measurement will be presented. Finally, conclusion will be provided in the last section.

\section{Antenna Design}

This section presents the design of the dipole antenna with embedded interdigital lines [18-20], as the structure shown in Fig. 1. The antenna is based on a planar dipole structure with a reflector. The copper plate with thickness of $1.5 \mathrm{~mm}$ was employed. Both a single dipole antenna and array antennas were designed and investigated using the CST Studio Suit. All details of the antenna design will be shown in the following subsections.

\subsection{Design of a Dipole Antenna with Interdigital Lines and a Reflector}

The rectangular patch dipole antenna with a length of $\lambda / 2$ was designed and simulated at resonant frequency of $1.8 \mathrm{GHz}$ (LTE band: $1.72-1.83 \mathrm{GHz}$ ) as shown in Fig. 2(a). Size of each patch is $70.9 \mathrm{~mm} \times 66 \mathrm{~mm}$. This conventional dipole is compared to the proposed interdigital structure in Fig. 2(b). As a result of $\left|S_{11}\right|$ shown in Fig. 3, the harmonic frequency band of the conventional antenna without inter-

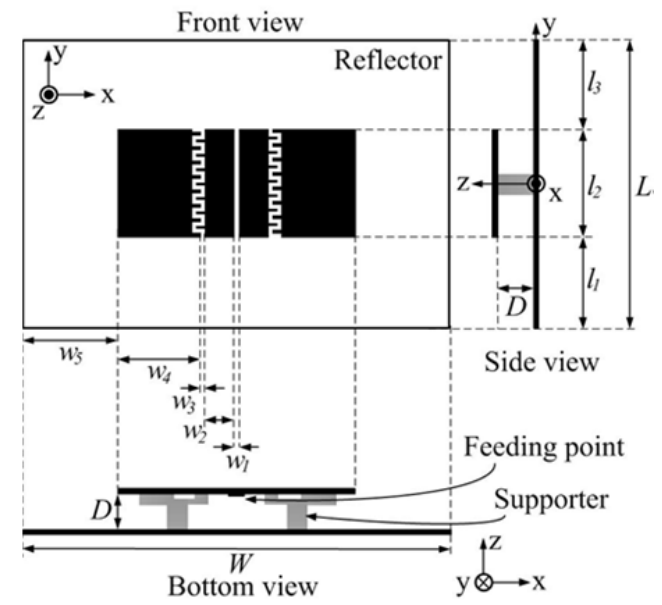

Fig. 1. Symmetrical configuration element of the antenna.

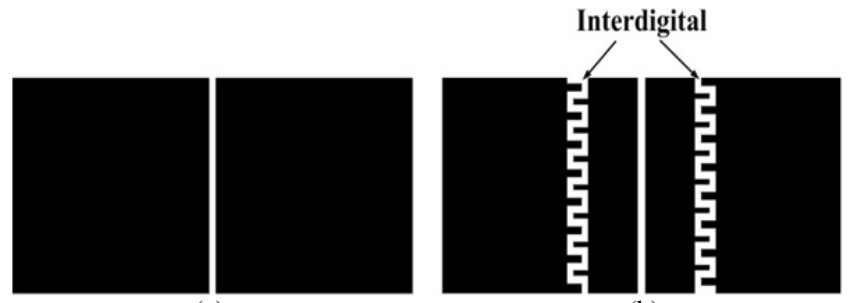

(a)

(b)

Fig. 2. The square elements of dipole antenna without interdigital and (b) with interdigital.

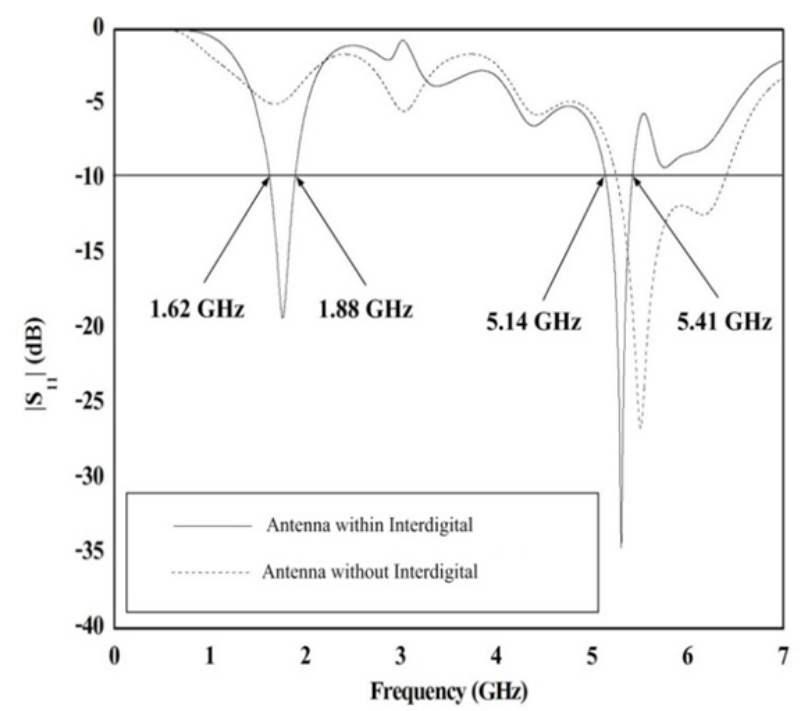

Fig. 3. Comparison of $\left|S_{11}\right|$ for the dipole antennas with and without interdigital structure.

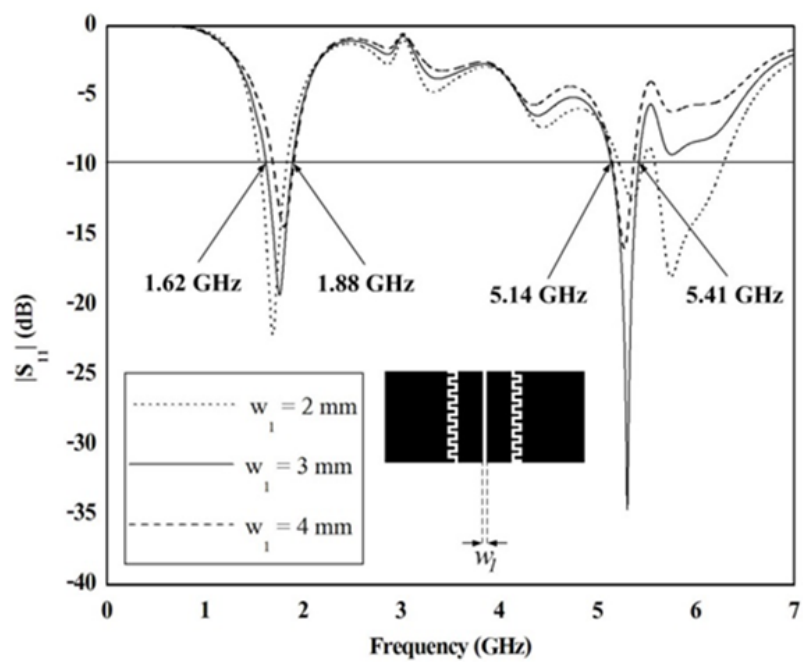

Fig. 4. Comparison of $\left|S_{11}\right|$ for the effect of dipole gap when varying $\mathrm{W}_{1}$ from $2 \mathrm{~mm}$ to $4 \mathrm{~mm}$.

digital structure does not cover WLAN application band $(5.15-5.35 \mathrm{GHz})$. However, with the proposed interdigital technique, the harmonic frequency band at $5.2 \mathrm{GHz}$ could be adjusted to cover the required WLAN band caused by changing capacitive value of the dipole patch. This capacitive value depends on sizes of fingers and gaps of the interdigital structure. Therefore, some interdigital parameters of the proposed antenna in Fig. 1 including $w_{1}$ and $w_{3}$ were investigated. The parameter $w_{1}$ was then varied from 2 to 
$4 \mathrm{~mm}$ when other parameters were fixed as initial values of $w_{2}=18 \mathrm{~mm}, w_{3}=2.5 \mathrm{~mm}, w_{4}=50.4 \mathrm{~mm}$, and $D=14 \mathrm{~mm}$. It is clearly seen in Fig. 4 that the parameter $w_{1}$ slightly affects on both frequency bands. However, the proper distance of gap $w_{1}$ is $3 \mathrm{~mm}$ that results to better matching with the $\left|\mathrm{S}_{11}\right|$ lesser than $-10 \mathrm{~dB}$. The bandwidths are obtained to be $1.62-1.88 \mathrm{GHz} \quad(260 \mathrm{MHz})$ and $5.14-5.41 \mathrm{GHz}$ $(270 \mathrm{MHz})$ for the fundamental and harmonic frequency bands, respectively. Figure 5 shows simulated results when varying the interdigital gap $w_{3}$ between 1.5 and $3.5 \mathrm{~mm}$. It is clearly seen that the fundamental frequency has a little effect. At minimum gap of $1.5 \mathrm{~mm}$, the capacitive value is higher, resulting in shifting the harmonic frequency close to the fundamental frequency. At maximum gap of $3.5 \mathrm{~mm}$, the harmonic frequency is shifted away from the fundamental frequency due to lower capacitance. Therefore, the proper distance of gap to increase capacitive value on the patch antenna for resonance at the second harmonic frequency is $2.5 \mathrm{~mm}$, which results to the resonance frequency at $5.2 \mathrm{GHz}$ as desired to cover the bandwidth between 5.14 and $5.41 \mathrm{GHz}(270 \mathrm{MHz})$.

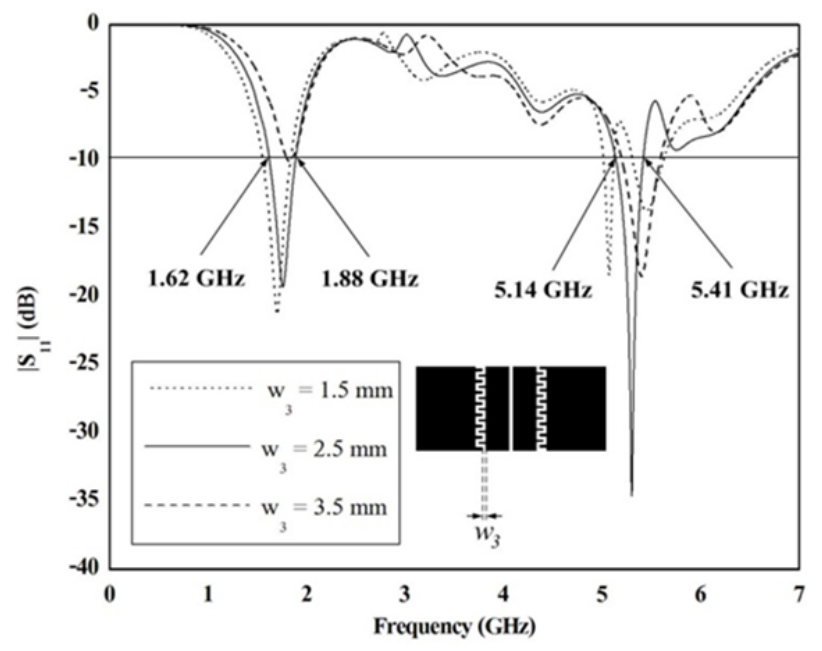

Fig. 5. Comparison of $\left|S_{11}\right|$ for the effect of interdigital gap when varying $w_{3}$ from $1.5 \mathrm{~mm}$ to $3.5 \mathrm{~mm}$.

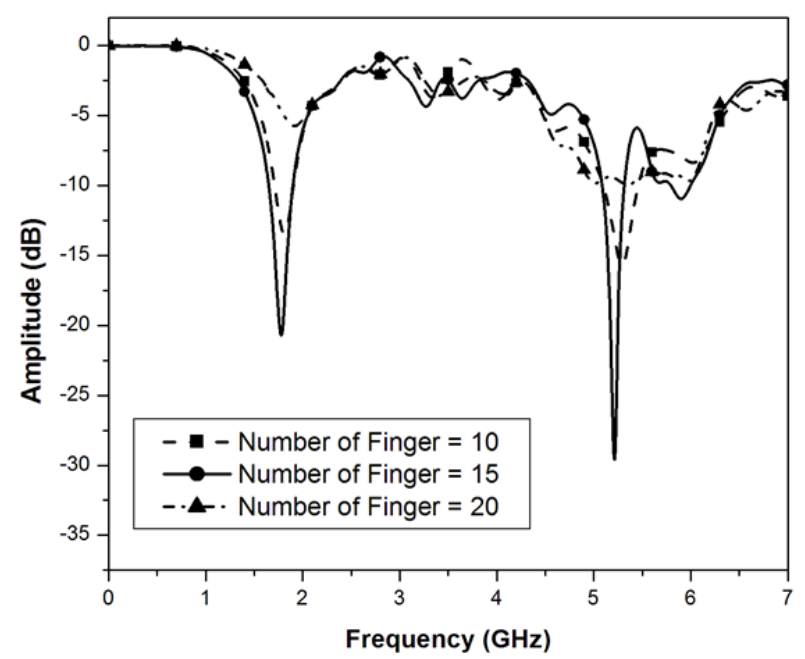

Fig. 6. Comparison $\left|S_{11}\right|$ for the effect number of finger when varying number of fingers from 10 to 20 .

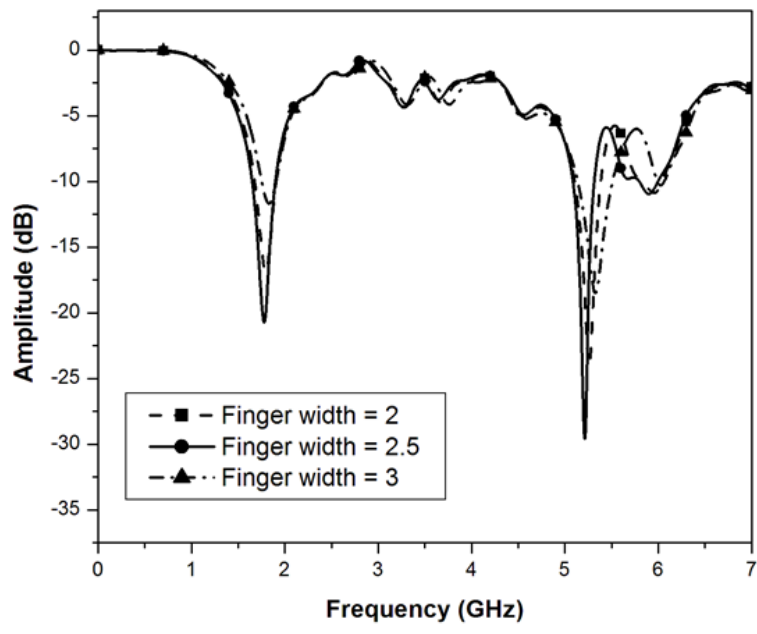

Fig. 7. Comparison $\left|S_{11}\right|$ for the effect of finger width when varying from $2 \mathrm{~mm}$ to $3 \mathrm{~mm}$.

In addition to control harmonic frequency, it can be seen that the good impedance matching is obtained with the $\left|\mathrm{S}_{11}\right|$ lower than $-10 \mathrm{~dB}$ at both frequency bands. The final $\left|\mathrm{S}_{11}\right|$ of the proposed antenna when $w_{1}=3 \mathrm{~mm}$ and $w_{2}=2.5 \mathrm{~mm}$ is already shown in Fig. 3 . The number of fingers and finger width were also investigated. Figure 6 shows the results when varying the number of fingers to be 10,15 and 20. It is found that the number of fingers slightly affects to the frequency band. However, 15 fingers were chosen to give a suitable matching for both bands. Then, the finger width was varied between 2 and $3 \mathrm{~mm}$, resulting in the frequency response as shown in Fig. 7. It is clearly seen that the finger width has the effect on shifting the second harmonic band. Nevertheless, the finger width of $2.5 \mathrm{~mm}$ was chosen for covering the application bands of LTE and WLAN. It is clearly seen that the dipole with interdigital lines can control the second harmonic as desired without affecting to the fundamental frequency. All important parameter dimensions of the proposed interdigital capacitors are shown in Tab. 1.

Next, a reflector was applied to the dipole antenna in order to increase its gain. Figure 8 shows the structure of the antenna with a reflector. The reflector size is $232 \mathrm{~mm} \times 153.5 \mathrm{~mm}$ to cover the dipole. Between the antenna and the reflector, a support material with low effect on antenna radiation, lightweight and high power handling was needed. The material of polyoxymethylene (POM) was then chosen, as the structure shown in Fig. 1. Normally, the distance between the antenna and reflector $D$ is approximately about $\lambda / 4$. However, the distance was slightly changed when using interdigital structure with the dipole antenna. To find the appropriate value of $D$, it was then varied from 14 and $41.6 \mathrm{~mm}$.

\begin{tabular}{|c|l|c|}
\hline Parameter & \multicolumn{1}{|c|}{ Description } & Size (cm) \\
\hline$w_{1}$ & feeding gap & 0.3 \\
\hline$w_{2}$ & width of smaller side of each element & 1.8 \\
\hline$w_{3}$ & width of incision gap & 0.25 \\
\hline$w_{4}$ & width of larger side of each element & 5.04 \\
\hline
\end{tabular}

Tab. 1. Optimal parameters of the proposed dipole antenna. 


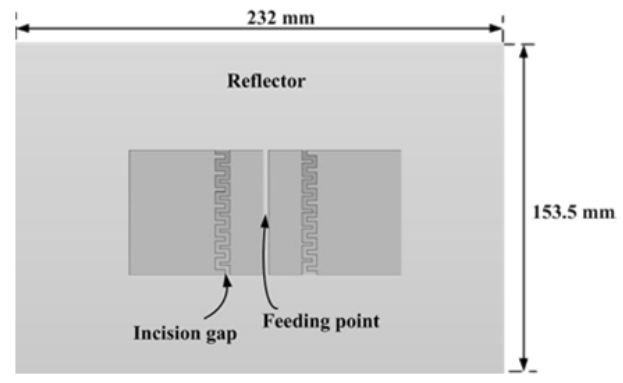

Fig. 8. Structure of the proposed antenna with a reflector.

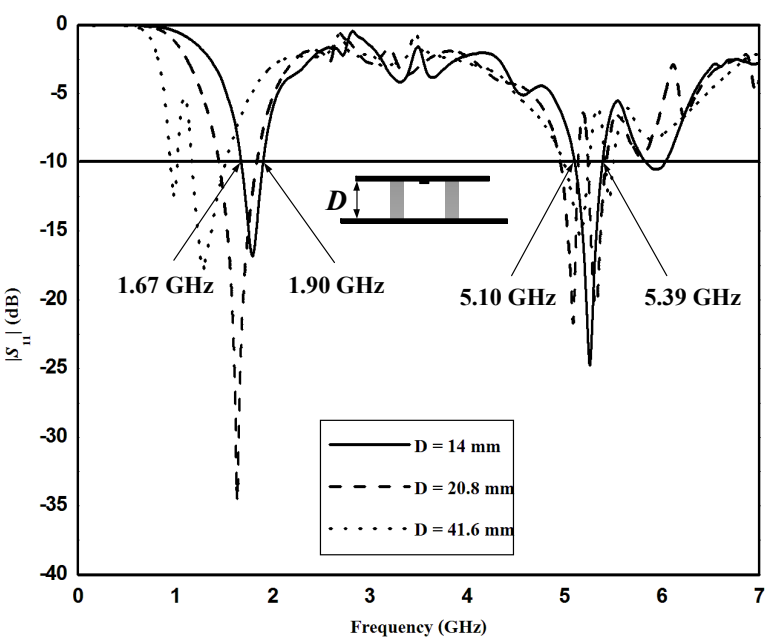

Fig. 9. Optimal distance $D$ between the antenna element and the reflector

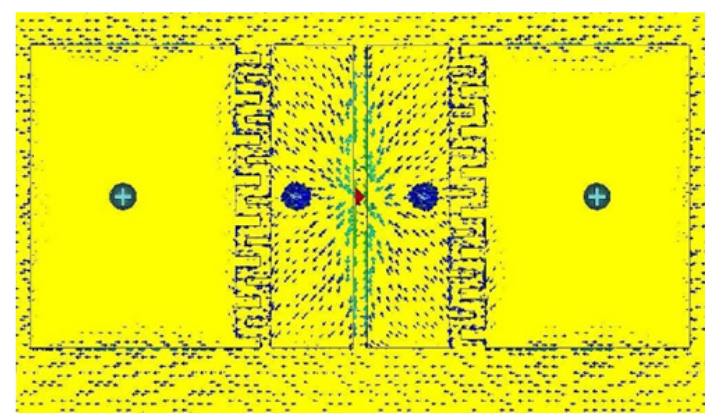

(a)

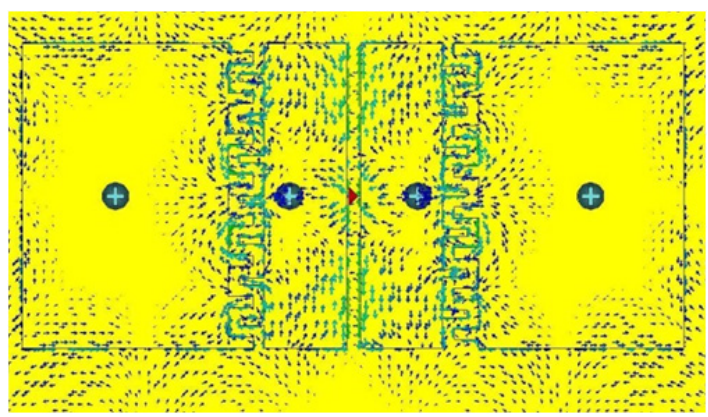

(b)

Fig. 10. Simulated surface currents on the dipole antenna (a) $1.8 \mathrm{GHz}$ and (b) $5.2 \mathrm{GHz}$

It is found that the distance $D$ affects to the frequency shifting at both fundamental and harmonic frequency bands. The most appropriate distance is $14 \mathrm{~mm}$, that results to good impedance matching with $|\mathrm{S} 11|$ lesser than $-10 \mathrm{~dB}$.
The bandwidths of $1.67-1.9 \mathrm{GHz}(230 \mathrm{MHz})$ and between 5.1 and $5.39 \mathrm{GHz}(290 \mathrm{MHz})$ are obtained for the fundamental band of $1.8 \mathrm{GHz}$ and the second harmonic band of $5.2 \mathrm{GHz}$, respectively. Simulated surface currents of the proposed dipole antenna are shown in Fig. 10. Figure 11 also shows the current distributions at the fundamental and second harmonic frequencies. It is clearly seen that the higher band at $5.2 \mathrm{GHz}$ has more surface current and current distribution at the fingers of interdigital structure than the lower band at $1.8 \mathrm{GHz}$. This means that the dipole with interdigital capacitor has a strong effect at harmonic frequency.

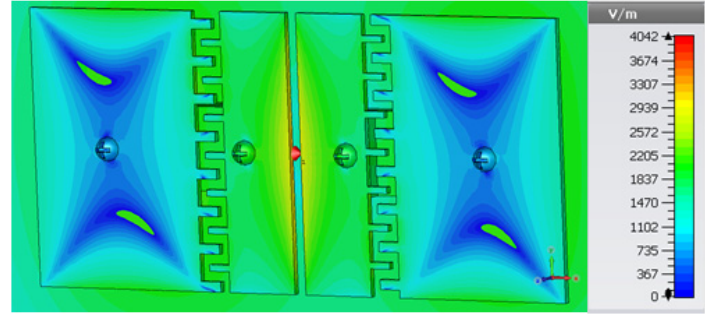

(a)

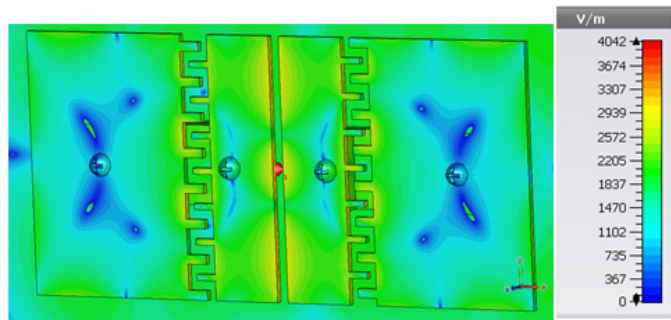

(b)

Fig. 11. Simulated current distribution of the dipole antenna: (a) $1.8 \mathrm{GHz}$ and (b) $5.2 \mathrm{GHz}$.

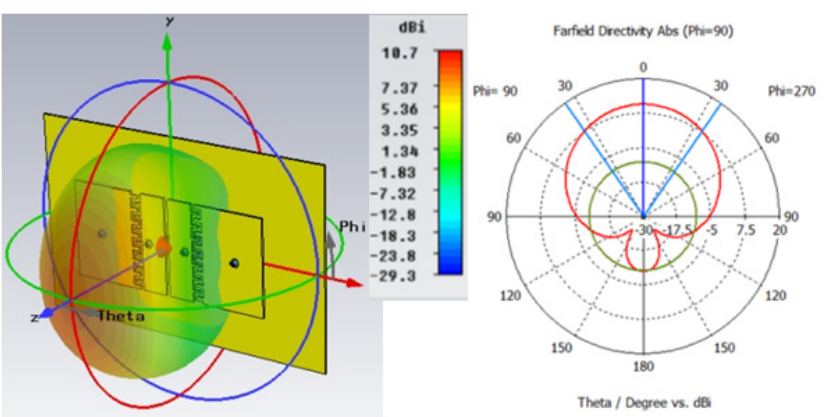

(a)

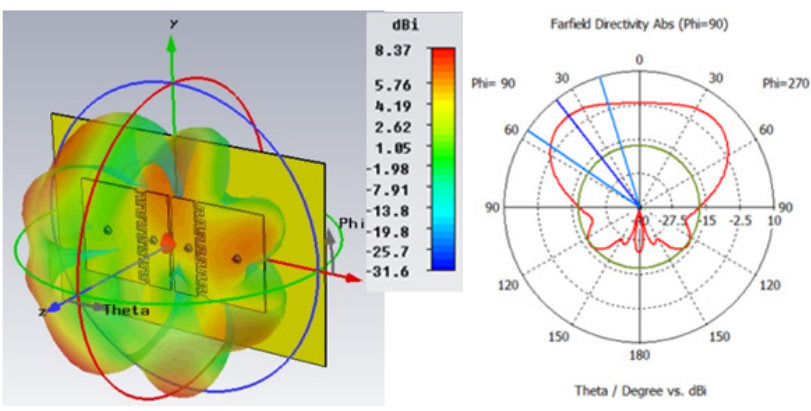

(b)

Fig. 12. Simulated radiation patterns of the dipole antenna: (a) $1.8 \mathrm{GHz}$ and (b) $5.2 \mathrm{GHz}$. 


\begin{tabular}{|c|l|c|}
\hline Parameter & \multicolumn{1}{|c|}{ Description } & Size(cm) \\
\hline $\mathrm{L}$ & length of reflector & 15.3 \\
\hline$W$ & width of reflector & 21.5 \\
\hline$D$ & distance between array antenna and reflector & 1.4 \\
\hline$w_{1}$ & feeding gap & 0.3 \\
\hline$w_{2}$ & width of smaller side of each element & 1.8 \\
\hline$w_{3}$ & width of incision gap & 0.25 \\
\hline$w_{4}$ & width of larger side of each element & 5.04 \\
\hline$w_{5}$ & distance from reflector to antenna element & 3.56 \\
\hline$l_{1}$ & distance between of each antenna element & 3.5 \\
\hline$l_{2}$ & length of each element & 6.65 \\
\hline$l_{3}$ & $\begin{array}{l}\text { distance from upper reflector to upper } \\
\text { antenna element }\end{array}$ & 3.57 \\
\hline
\end{tabular}

Tab. 2. Optimal parameters of the dipole antenna with the reflector.

\begin{tabular}{|l|c|c|}
\hline \multicolumn{1}{|c|}{ Property } & $\mathbf{1 . 8} \mathbf{~ G H z}$ & $\mathbf{5 . 2} \mathbf{~ G H z}$ \\
\hline Angular beamwidth (degree) & 42.1 & 22.9 \\
\hline Main lobe direction (degree) & 0 & 29 \\
\hline Back lobe (dB) & -10.1 & -23.29 \\
\hline Side lobe (dB) & -20.8 & -13.3 \\
\hline Gain (dBi) & 10.71 & 8.37 \\
\hline
\end{tabular}

Tab. 3. Radiation properties of the antenna with the reflector.

Figure 12 shows the simulated radiation patterns which are directional at both frequency bands. The simulated gain at $1.8 \mathrm{GHz}$ is $10.7 \mathrm{~dB}$ at direction 0 degree and size of main lobe is 42.1 degree, while at $5.2 \mathrm{GHz}$ the gain is $8.37 \mathrm{~dB}$ at the best direction of 22.9 degree. All key parameters of the dipole antenna with the reflector in Fig. 1 are shown in Tab. 2. Also the important characteristics of the antenna are included in Tab. 3. This antenna could be used for indoor applications.

\subsection{Design of Array Antennas}

From the previous subsection, it is found that the low antenna gain is obtained. To develop for higher gain, the array structure must be employed. Therefore, two dipole antennas were connected to be an array as shown in Fig. 13. The distance $l_{1}$ between each antenna affects the radiation patterns and gains. It is found that the appropriate distance is $3.5 \mathrm{~cm}$, resulting in highest gain at both resonance frequencies. Table 4 shows all key parameters of the array antenna. Simulated $\left|\mathrm{S}_{11}\right|$ of the proposed array antenna is shown in Fig. 14, which has dual resonance frequencies as desired at $1.8 \mathrm{GHz}$ and $5.2 \mathrm{GHz}$. There are bandwidths of $1.67-1.89 \mathrm{GHz}(220 \mathrm{MHz})$ and between 5.1 and $5.39 \mathrm{GHz}(290 \mathrm{MHz})$, respectively, which are equal to the single dipole antenna. The simulated radiation patterns are also shown in Fig. 15. It is clearly seen that the array antenna radiates the directional patterns, the same as the proposed dipole antenna patterns but higher gain. The gains of array antenna are $12.6 \mathrm{~dB}$ at $1.8 \mathrm{GHz}$ and $9.84 \mathrm{~dB}$ at $5.2 \mathrm{GHz}$. With these higher gains, the proposed array antenna may be suitable for outdoor applications.

The radiation pattern characteristics of array antenna with two elements are concluded in Tab. 5. From this table, it is shown that the directions of main lobes are at the same for both bands, but it is split into two maximums at 23 degree for the second band.

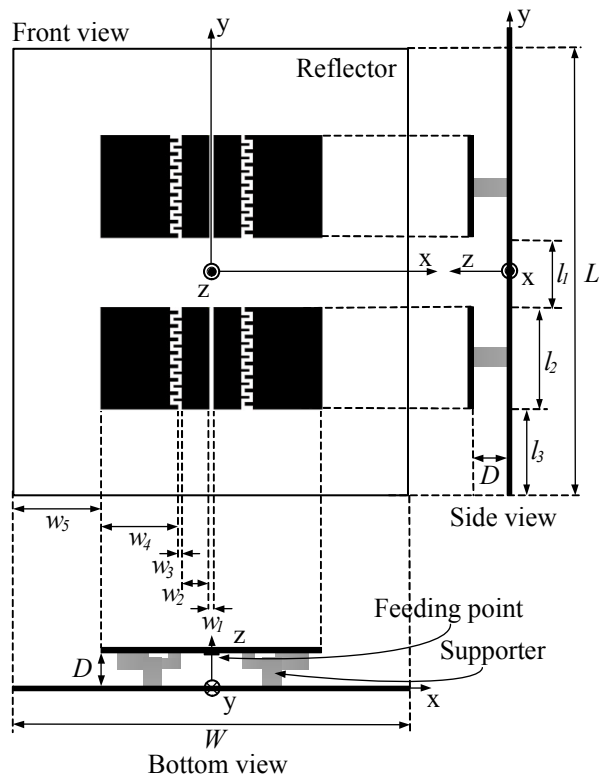

Fig. 13. Layout of the array antenna with two elements.

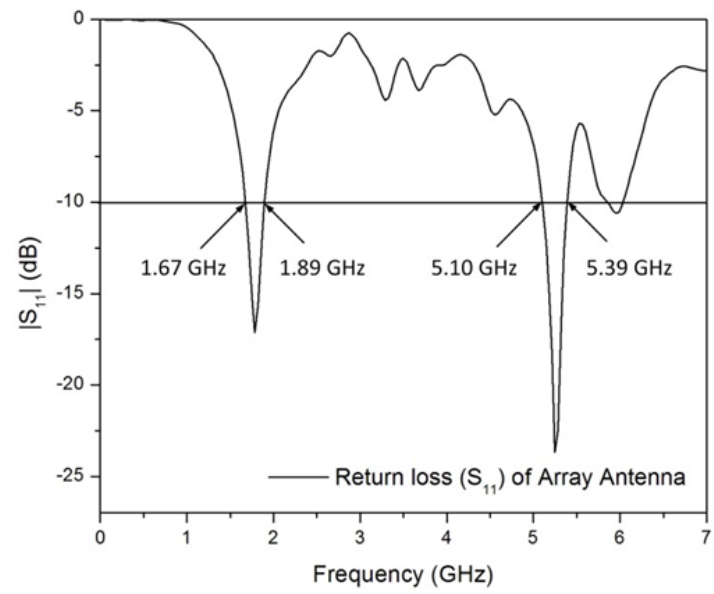

Fig. 14. Simulated result of array antenna with two elements.

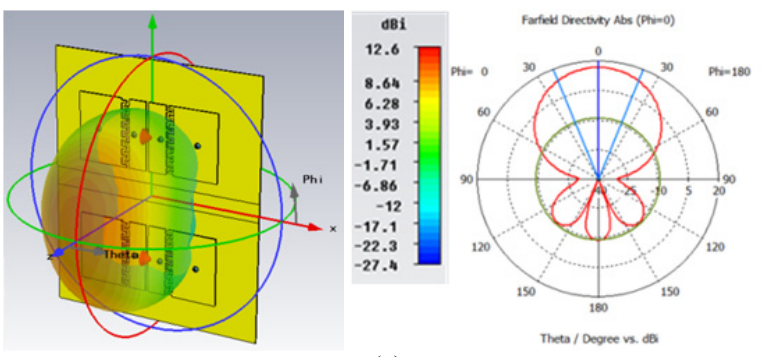

(a)

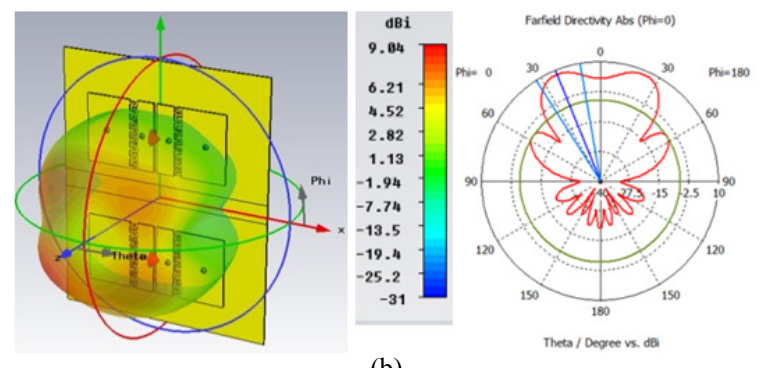

(b)

Fig. 15. Simulated radiation pattern of the array antenna at: (a) $1.8 \mathrm{GHz}$ and (b) $5.2 \mathrm{GHz}$. 


\begin{tabular}{|c|l|c|}
\hline Parameter & \multicolumn{1}{|c|}{ Description } & Size(cm) \\
\hline $\mathrm{L}$ & length of reflector & 24.5 \\
\hline$W$ & width of reflector & 21.5 \\
\hline$D$ & $\begin{array}{l}\text { distance between array antenna and } \\
\text { reflector }\end{array}$ & 1.4 \\
\hline$w_{1}$ & feeding gap & 0.3 \\
\hline$w_{2}$ & width of smaller side of each element & 1.8 \\
\hline$w_{3}$ & width of incision gap & 0.25 \\
\hline$w_{4}$ & width of larger side of each element & 5.04 \\
\hline$w_{5}$ & distance from reflector to antenna element & 3.56 \\
\hline$l_{1}$ & distance between of each antenna element & 3.5 \\
\hline$l_{2}$ & length of each element & 6.65 \\
\hline$l_{3}$ & $\begin{array}{l}\text { distance from upper reflector to upper } \\
\text { antenna element }\end{array}$ & 3.57 \\
\hline
\end{tabular}

Tab. 4. Parameters of the array antenna with two elements.

\begin{tabular}{|l|c|c|}
\hline \multicolumn{1}{|c|}{ Property } & $\mathbf{1 . 8 ~ G H z}$ & $\mathbf{5 . 2} \mathbf{~ G H z}$ \\
\hline Angular beamwidth (degree) & 48 & 33.25 \\
\hline Main lobe direction (degree) & 0 & 23 \\
\hline Back lobe (dB) & -13 & -19 \\
\hline Side lobe (dB) & -19.5 & -12.3 \\
\hline Gain (dBi) & 12.6 & 9.84 \\
\hline
\end{tabular}

Tab. 5. Properties of radiation pattern for the array antenna with two elements.

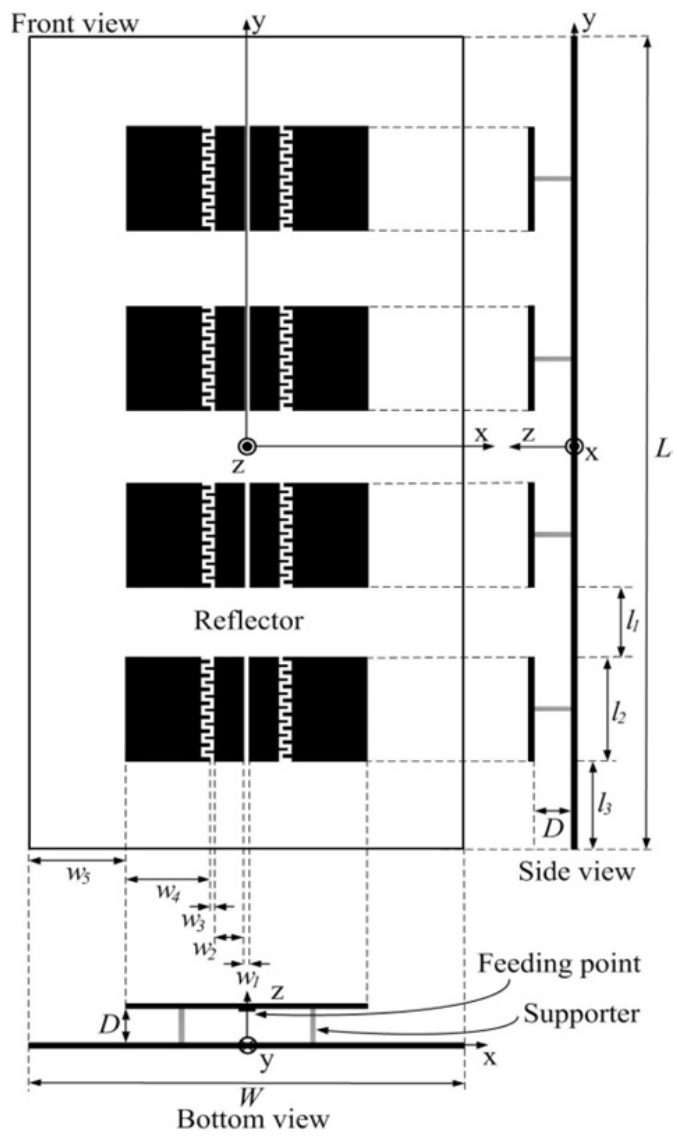

Fig. 16. Layout of the array antenna with four elements.

To further increase the antenna gain suitable for a standard base station, the array antenna with 4 elements was presented as a layout shown in Fig. 16. The simulated result of the array antenna with four elements is shown in Fig. 17. The resonance frequencies are still at $1.8 \mathrm{GHz}$ and

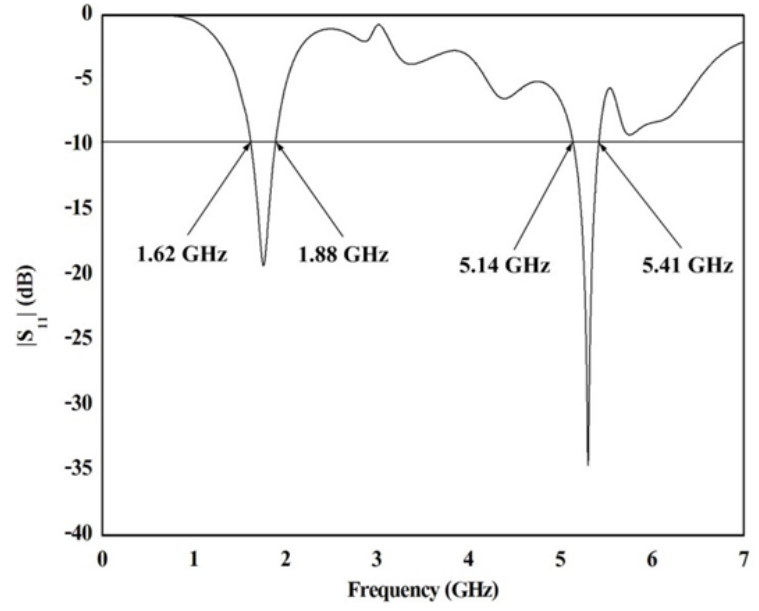

Fig. 17. Simulation result of the array antenna with 4 elements.

\begin{tabular}{|c|l|c|}
\hline Parameter & \multicolumn{1}{|c|}{ Description } & Size(cm) \\
\hline $\mathrm{L}$ & length of reflector & 55.85 \\
\hline$W$ & width of reflector & 21.5 \\
\hline$D$ & $\begin{array}{l}\text { distance between array antenna and } \\
\text { reflector }\end{array}$ & 1.4 \\
\hline$w_{1}$ & feeding gap & 0.3 \\
\hline$w_{2}$ & width of smaller side of each element & 1.8 \\
\hline$w_{3}$ & width of incision gap & 0.25 \\
\hline$w_{4}$ & width of larger side of each element & 5.1 \\
\hline$w_{5}$ & distance from reflector to antenna element & 4.3 \\
\hline$l_{1}$ & distance between of each antenna element & 6.75 \\
\hline$l_{2}$ & length of each element & 6.75 \\
\hline$l_{3}$ & $\begin{array}{l}\text { distance from upper reflector to upper } \\
\text { antenna element }\end{array}$ & 4.3 \\
\hline
\end{tabular}

Tab. 6. Parameters of the array antenna with 4 elements.

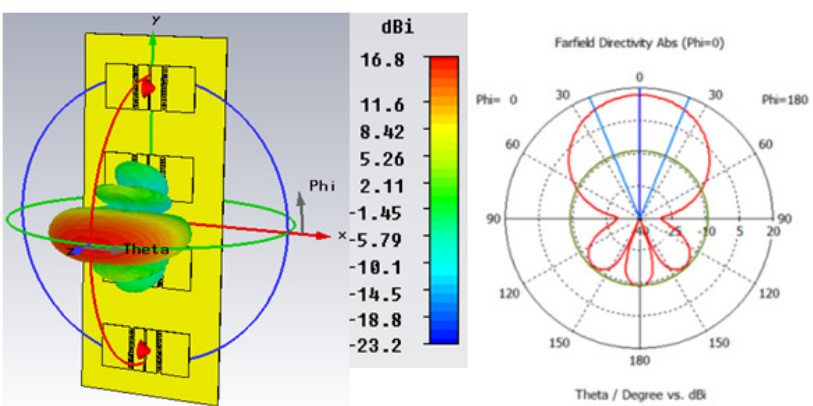

(a)

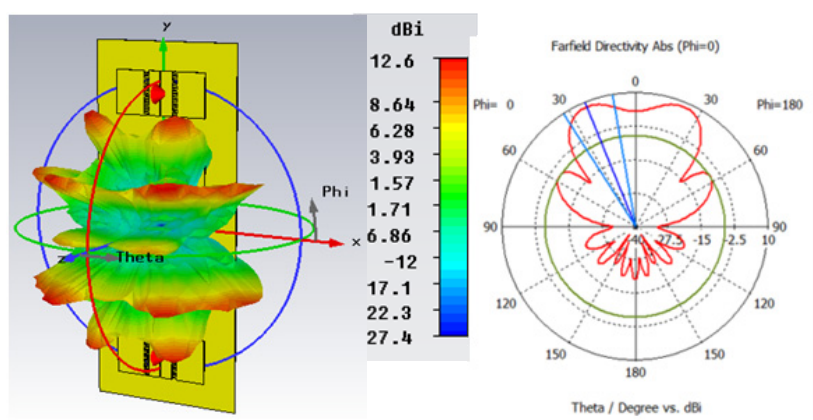

(b)

Fig. 18. Simulated radiation patterns of the array antenna with four elements at (a) $1.8 \mathrm{GHz}$ and (b) $5.2 \mathrm{GHz}$.

$5.2 \mathrm{GHz}$ and the bandwidths are $1.68-1.88 \mathrm{GHz}$ (260 MHz) and 5.14-5.41 GHz (270 MHz), respectively. 


\begin{tabular}{|l|c|c|}
\hline \multicolumn{1}{|c|}{ Property } & $\mathbf{1 . 8} \mathbf{~ G H z}$ & $\mathbf{5 . 2} \mathbf{~ G H z}$ \\
\hline Angular beamwidth (degree) & 43.5 & 22.3 \\
\hline Main lobe direction (degree) & 0 & 22 \\
\hline Back lobe (dB) & -8.87 & -20.25 \\
\hline Side lobe $(\mathrm{dB})$ & -25.7 & -14.2 \\
\hline Gain $(\mathrm{dBi})$ & 16.84 & 12.6 \\
\hline
\end{tabular}

Tab. 7. Properties of radiation pattern for the array antenna with four elements.

The simulated radiation patterns are also shown in Fig. 18. It is found that at $1.8 \mathrm{GHz}$, the antenna radiates directionally at 0 degree with gain of $16.8 \mathrm{~dB}$ as shown in Fig. 18(a). In Fig. 18(b), the main lobe is split into two maximums in the direction of 22 degree at $5.2 \mathrm{GHz}$ with gain of $12.6 \mathrm{~dB}$. The size of the proposed array antenna is $23.2 \mathrm{~cm} \times 55.8 \mathrm{~cm}$. Table 6 concludes all key parameters of the antenna structure in Fig. 16. The properties of radiation pattern are also shown in Tab. 7. This proposed antenna can be potentially used for outdoor applications as a dual band base station antenna because of its good performances, especially high gain and high power handling capacity.

The proposed array antenna is smaller than the conventional base station antenna. Also, it is easy to design and control harmonic frequency or the second band frequency as needed. Next, antenna fabrication and measurement results will be presented.

\section{Implementation and Results}

After designing the proposed antenna as mentioned in previous sections, this section presents the antenna fabrication. The interdigital dipole antenna with the reflector was firstly constructed and then the array antenna using interdigital dipole antenna with two elements was implemented in order to verify the concept of gain improvement. The proposed dipole antenna with the reflector fabricated on copper plates with thickness of $1.5 \mathrm{~mm}$ was fed by the coaxial RG-142 cable with $50 \Omega$ characteristic impedance. Another end of the coaxial cable was connected with SMA-51 as shown in Fig. 19. Figure 20 shows the picture of the completed antenna prototype. The proposed interdigital dipole antenna as shown in Fig. 21 was then measured by using Agilent 8791ES network analyzer, resulting in the same resonant frequencies as simulated.

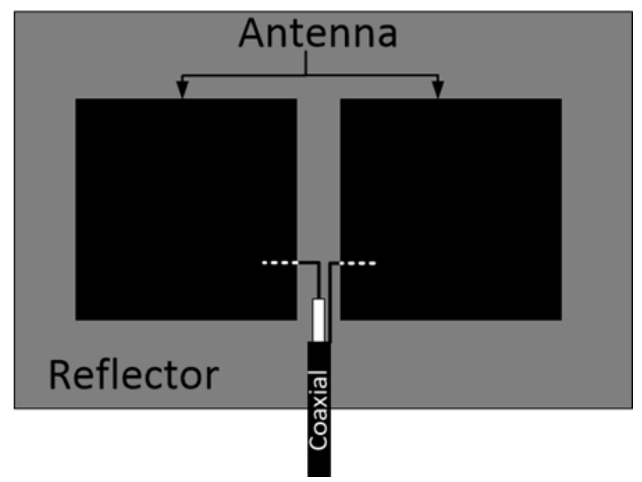

Fig. 19. Schematic of the proposed dipole antenna.

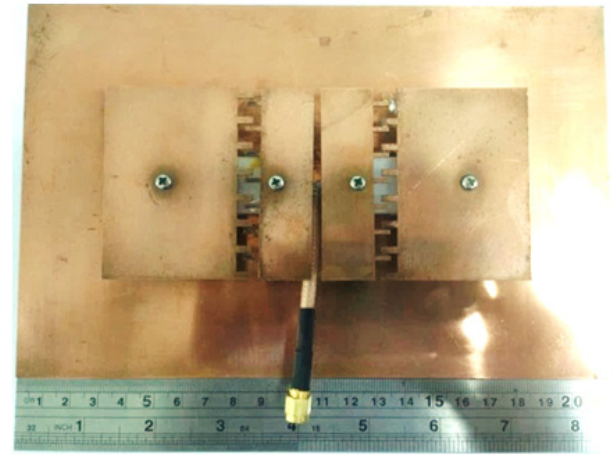

Fig. 20. Photograph of the fabricated dipole antenna.

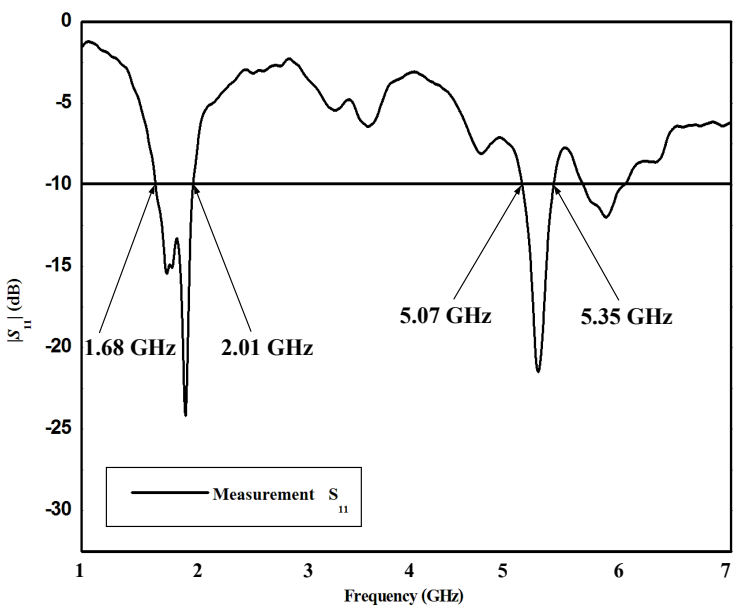

Fig. 21. Measured result of the dipole antenna.

From the measurement results, the values of return losses $\mathrm{S}_{11}$ at the fundamental and the second harmonic frequencies are $-24 \mathrm{~dB}$ and $-23 \mathrm{~dB}$, respectively. The bandwidths are $300 \mathrm{MHz}(1.68-2.01 \mathrm{GHz})$ and $280 \mathrm{MHz}$ $(5.07-5.35 \mathrm{GHz})$, respectively. Radiation patterns as shown in Fig. 22 are directional in both XZ and YZ planes for copolarization and non-directional in both $\mathrm{XZ}$ and $\mathrm{YZ}$ planes for cross-polarization. The array antenna with two elements was then implemented as schematic shown in Fig. 23, which two interdigital dipoles are connected using RG-142 coaxial cable with $50 \Omega$. A power splitter was employed to combine those two dipole elements and then the proposed array antenna was mounted above the reflector using POM. The fabricated array antenna was measured by Agilent 8791ES network analyzer, resulting in the same resonant frequencies as simulated. From the measurement results as shown in Fig. 25, the values of return losses $S_{11}$ are $-17 \mathrm{~dB}$ and $-24 \mathrm{~dB}$ for the fundamental and the second resonant frequencies, respectively.

The bandwidths of both bands are $390 \mathrm{MHz}$ (1.62 to $2.01 \mathrm{GHz})$ and $620 \mathrm{MHz}(4.93-5.55 \mathrm{GHz})$, respectively. For radiation patterns at $1.8 \mathrm{GHz}$, there are directional patterns on both $\mathrm{XZ}$ and $\mathrm{YZ}$ planes for co-polarizations with small back lobe and lower cross-polarization as shown in Fig. 26(a). At $5.2 \mathrm{GHz}$, the radiation patterns are also directional with lower cross-polarization on both $\mathrm{XZ}$ and YZ planes. That means the proposed array antenna still has directional patterns with high gain and works well for copolarizations. 


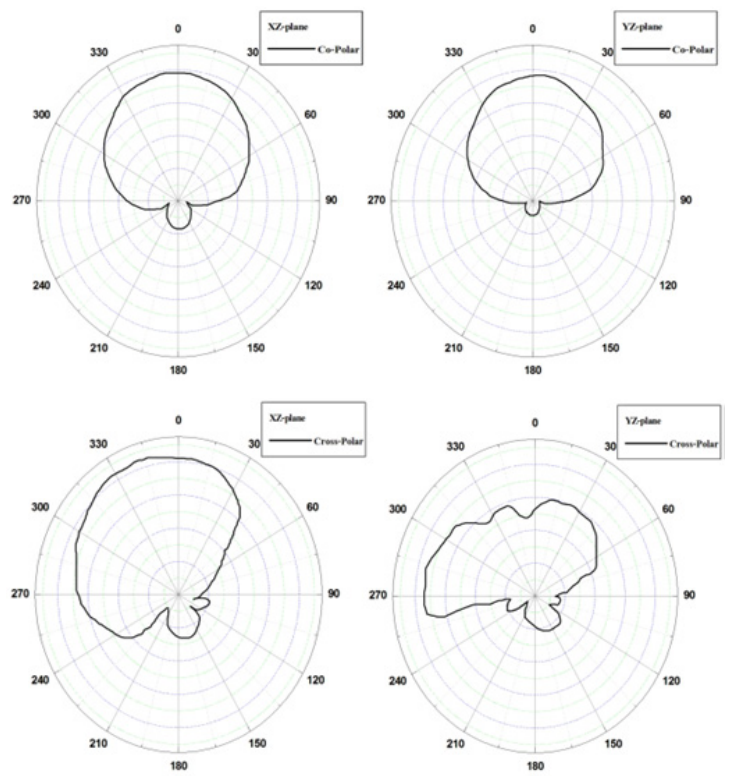

(a)

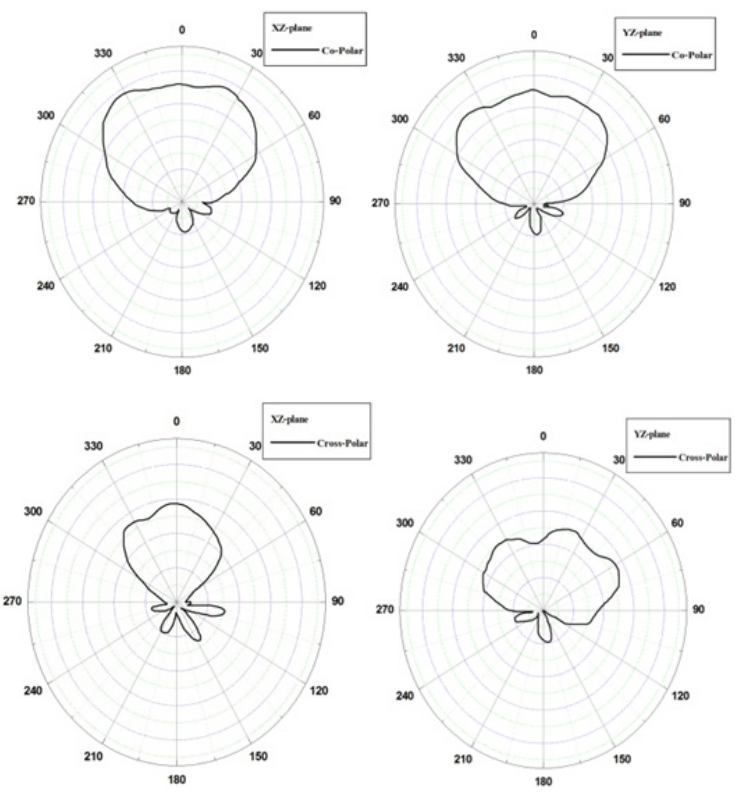

(b)

Fig. 22. Measured radiation patterns of the dipole antenna at (a) $1.8 \mathrm{GHz}$ and (b) $5.2 \mathrm{GHz}$.

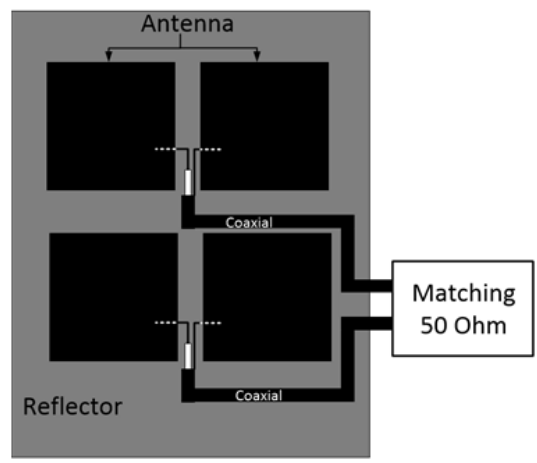

Fig. 23. Schematic of the proposed array antenna.

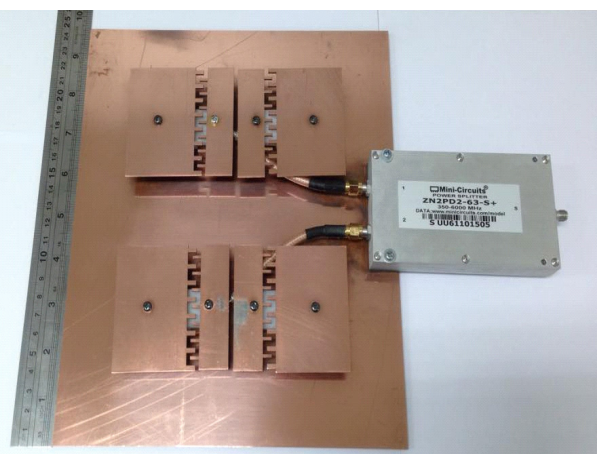

Fig. 24. Photograph of the fabricated array antenna.

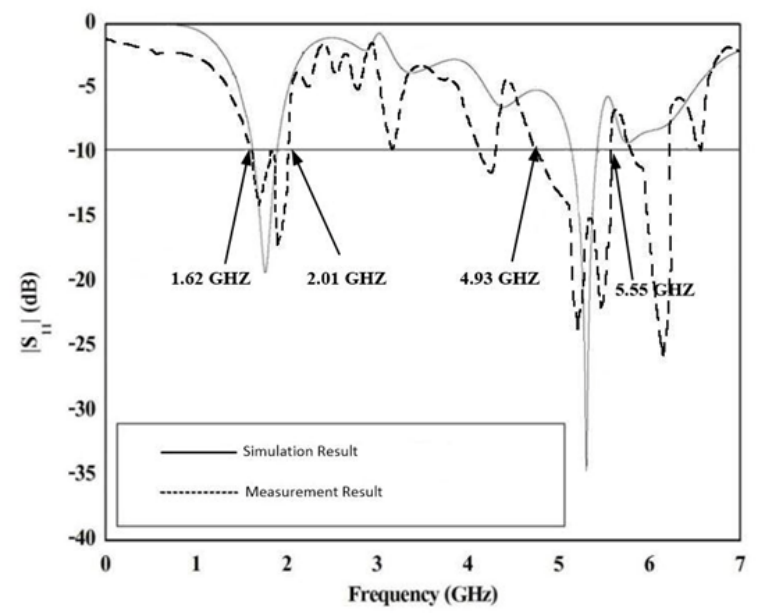

Fig. 25. Comparison of $\left|\mathrm{S}_{11}\right|$ between simulation and measured result of the array antenna.

\section{Conclusions}

The interdigital dipole antenna has been designed and it is found that by using the proposed technique the second harmonic band can be freely tuned as desired by changing interdigital capacitive value. The proposed antennas can be operated at $1.8 \mathrm{GHz}$ and $5.2 \mathrm{GHz}$ bands. The results show good agreement between simulation and measurement with good impedance matching (return loss below $-10 \mathrm{~dB}$ ), good impedance bandwidth, high gain and high radiation efficiency. The proposed antennas also demonstrate good performances with high power handling capacity because of its copper plate structure and they can support LTE and WLAN systems as indoor and outdoor base station antennas.

\section{Acknowledgments}

This work has been supported by the Thailand Research Fund through the TRF Grant for New Researcher No. TRG5780231 and the TRF Senior Research Scholar Program Grant No. RTA5780010. 

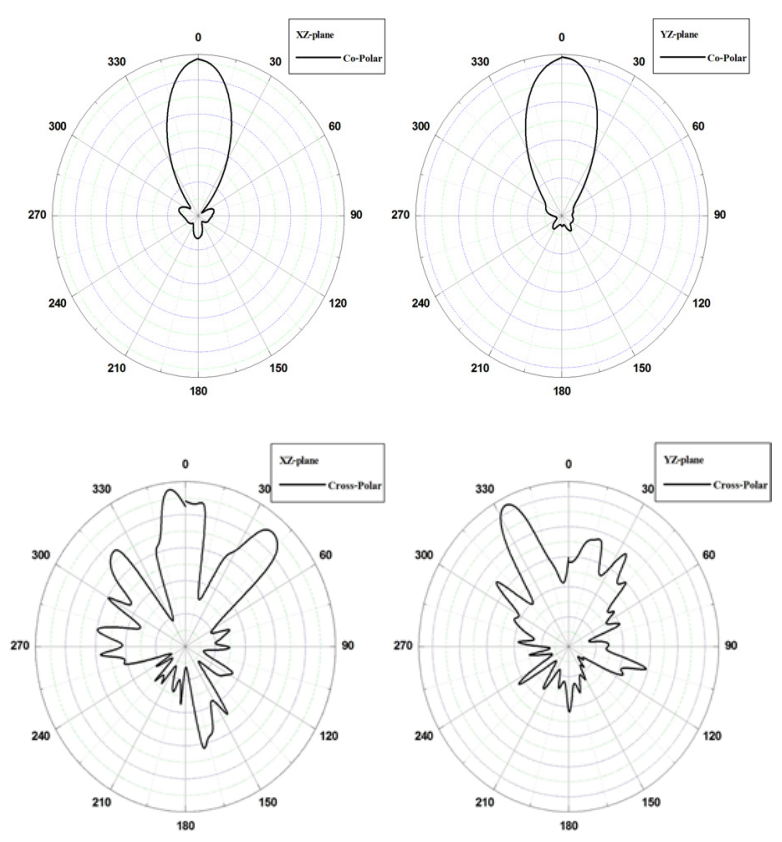

(a)

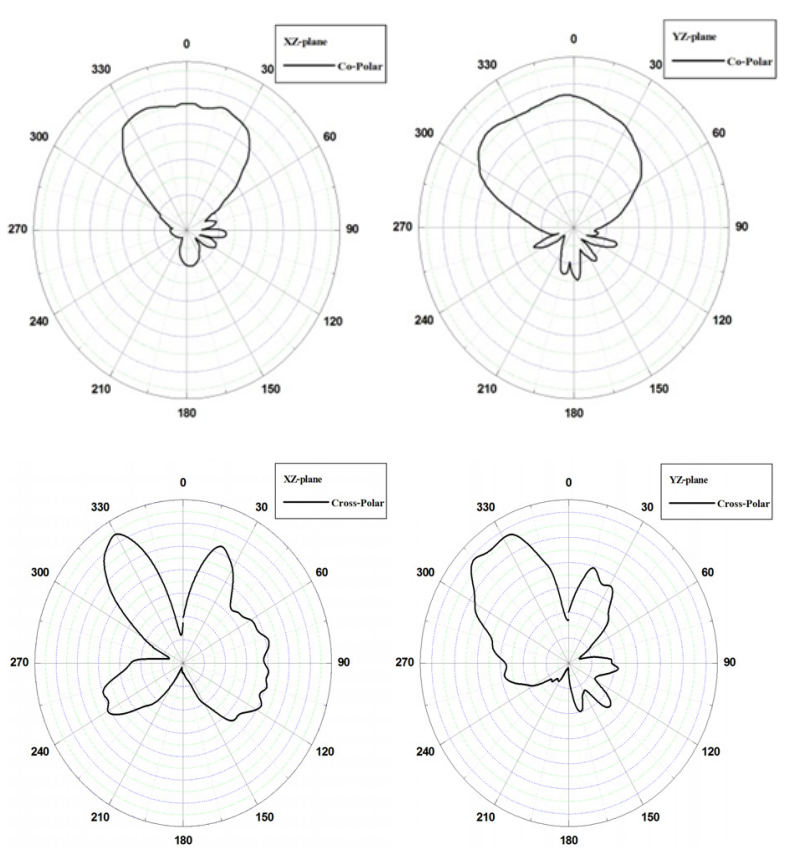

(b)

Fig. 26. Measured radiation patterns of the array antenna: (a) $1.8 \mathrm{GHz}$ and (b) $5.2 \mathrm{GHz}$.

\section{References}

[1] KingSley, N., ANAGNOStoU, D. E., TENTZERIS, M., PAPAPOLYMEROU, J. RF MEMS sequentially reconfigurable Sierpinski antenna on a flexible organic substrate with novel DCbiasing technique. Journal of Microelectromechanical Systems, 2007, vol. 16, no. 5, p. 1185-1192. DOI: 10.1109/JMEMS.2007.902462

[2] WERNER, D. H., GANGULY, S. An overview of fractal antenna engineering research. IEEE Antennas and Propagations Magazine, 2003, vol. 45, no. 1, p. 38-57. DOI: 10.1109/MAP.2003.1189650
[3] MARAGHECHI, P., ELEZZABI, A. Y. Fractal structures for THz radiation emitters. IEEE Journal of Selected Topics in Quantum Electronics, 2013, vol. 19, no. 1, p. 8400310 (10 p.). DOI: 10.1109/JSTQE.2012.2198196

[4] GUNDETI, P., GEORGE, T. K. Performance analysis of a compact directional monopole antenna. In Applied Electromagnetics Conference (AEMC). Kolkata (India), 2011, 4 p. DOI: 10.1109/AEMC.2011.6256794

[5] HONG-YAN LIANG, HONG-CHUN YANG, JING ZHANG. A cylindrical conformal directional monopole antenna for borehole radar application. IEEE Antennas and Wireless Propagation Letters, 2012, vol. 11, p. 1525-1528. DOI: 10.1109/LAWP.2012.2231852

[6] MOODY, R. A., SHARMA, S. K. Ultrawide bandwidth (UWB) planar monopole antenna backed by novel pyramidal-shaped cavity providing directional radiation patterns. IEEE Antennas and Wireless Propagation Letters, 2011, vol. 10, p. 1469-1472. DOI: 10.1109/LAWP.2011.2179513

[7] LI WEI, QIU JINGHUI, SUO YING. Design and simulation of novel ultra wideband planar reflector antenna. In International Conference on Microwave and Millimeter Wave Technology (ICMMT). Builin (China), Apr 2007, 4 p. DOI: 10.1109/ICMMT.2007.381265

[8] AGARWAL, K., NASIMUDDIN, ALPHONES, A. Wideband circularly polarized AMC reflector backed aperture antenna. IEEE Transactions on Antenna and Propagation, 2013, vol. 61, no. 3, p. 1456-1461. DOI: 10.1109/TAP.2012.2227446

[9] DONG-ZO KIM, HYUN-SUNG TAE, KYOUNG-SUB OH, MOON-QUE LEE, JONG-WON YU. Helical reflector antenna with a wideband CP for RFID reader. In Asia Pacific Microwave Conference. Singapore, Dec 2009. DOI 10.1109/APMC.2009.5384359

[10] JAYASINGHE, J. M. J. W., ANGUERA, J., UDUWAWALA, D. N. Genetic algorithm optimization of a high-directivity microstrip patch antenna having a rectangular profile. Radioengineering, 2013, vol. 22 , no. 3 , p. $700-707$

[11] GAO FENG, LEI ZHOU, ZHAO YAN, SHAN RUNHONG, QI YIHONG, HU YANG. Influence of cable routing for indoor multisystem omnidirectional antenna horizontal pattern ripple measurement. In 2014 IEEE International Symposium on Electromagnetic Compatibility (EMC). Raleigh (NC, USA), 2014, p. 418-422. DOI: 10.1109/ISEMC.2014.6899008

[12] LEI ZHOU, YONGCHANG JIAO, YIHONG QI, ZIBIN WENG, LIANG LU. Wideband ceiling-mount omnidirectional antenna for indoor distributed antenna systems. IEEE Antennas and Wireless Propagation Letters, 2014, vol. 13, p. 836-839. DOI: 10.1109/LAWP.2014.2319087

[13] QI WU, XIAOJING DING, AIXIN CHEN. A broadband dipole antenna for multiservice indoor distribution antenna system (MSIDAS). IEEE Antennas and Wireless Propagation Letters, 2015, vol. 14, p. 839-842. DOI: 10.1109/LAWP.2014.2381876

[14] NAYAN, M.K., JAMLOS, M. F., JAMLOS, M. A., LAGO, H. MIMO $2 \times 2$ RHCP array antenna for point-to-point communication. In IEEE Symposium on Wireless Technology and Applications (ISWTA). Kota Kinabalu (Malaysia), 2014, p. 121 to 124. DOI: $10.1109 /$ ISWTA.2014.6981169

[15] DONG-FANG GUAN, CAN DING, ZU-PING QIAN, YINGSONG ZHANG, WEN-QUAN CAO, DUTKIEWICZ, E. An SIWbased large-scale corporate-feed array antenna. IEEE Transactions on Antennas and Propagation, 2015, vol.63, no.7, p. 2969-2976. DOI: 10.1109/TAP.2015.2430369

[16] ZUBING WU, JIN PAN, SHA HU, SHUBO WEN, DEQIANG YANG. Design of a novel dual polarization wideband base station antenna. In IEEE Symposium on Intelligent Signal Processing and Communication Systems (ISPACS). Chengdu (China), 2010. DOI: 10.1109/ISPACS.2010.5704705 
[17] HUIQING ZHAI, QIQIANG GAO, CHANGHONG LIANG, RONGDAO YU, SHENG LIU. A dual-band high-gain basestation antenna for WLAN and WiMAX applications. IEEE Antennas and Wireless Propagation Letters, 2014, vol. 13, p. 876 to 879 . DOI: 10.1109/LAWP.2014.2321503

[18] YEJUN HE, ZHENGZHENG PAN, XUDONG CHENG, YUAN HE, JIAN QIAO, TENTZERIS, M. M. A novel dual-band, dualpolarized, miniaturized and low-profile base station antenna. IEEE Transaction on Antennas and Propagation, 2015, vol. 63, no. 12, p. 5399-5408. DOI: 10.1109/TAP.2015.2481488

[19] FENGLIU XU, XUEGUAN LIU, HUIPING GUO, YING WANG, LINGFENG MAO. A compact dual mode BPF base on interdigital structure. In Proceeding of the IEEE International Conference on Microwave and Millimeter Wave Technology (ICMMT). Chengdu (China), 2010, p. 1595-1597. DOI: 10.1109/ICMMT.2010.5524850

[20] ChOMTONG, P., AKKARAEKThalin, P. A MIMO antenna using interdigital technique for LTE and Wi-MAX on mobile applications. In International Symposium on Antennas and Propagation (ISAP). Hobart (Australia), Nov 2015, 4 p.

[21] MEESOMKLIN, S., CHOMTONG, P., AKKARAEKTHALIN, P. A compact mutiband BPF using step-impedance resonators with interdigital capacitors. Radioengineering, 2016, vol. 25 , no. 2, p. 258-267. DOI: $10.13164 /$ re.2016.0258

\section{About the Authors ...}

Pongsathorn CHOMTONG was born in Nonthaburi,
Thailand. He received his M.Eng. and Ph.D. degrees in Electrical Engineering from King Mongkut's University of Technology North Bangkok (KMUTNB), Thailand, in 2006 and 2011, respectively. In 2012, he joined the Department of Teacher Training in Electrical Engineering, KMUTNB, as an instructor. His current research interests include passive and active microwave circuits, wideband and multiband antennas, and telecommunication systems. He is a member of IEEE.

Prayoot AKKARAEKTHALIN received the B.Eng. and M.Eng. degrees in Electrical Engineering from King Mongkut's University of Technology North Bangkok (KMUTNB), Thailand, in 1986 and 1990, respectively, and the Ph.D. degree from the University of Delaware, Newark, USA, in 1998. From 1986 to 1988, he worked in the Microtek Laboratory, Thailand. In 1988, he joined the Department of Electrical Engineering, KMUTNB. His current research interests include passive and active microwave circuits, wideband and multiband antennas, and telecommunication systems. Dr. Prayoot is a members of IEEE, IEICE Japan, and ECTI Thailand. He was the Chairman for the IEEE MTT/AP/ED Thailand Joint Chapter during 2007 and 2008 and the President of ECTI Association from 2014 to 2015. He is now the head for Senior Research Scholar Project of Thailand Research Fund (TRF). 